\title{
Psychological Recovery from Coronary Artery Bypass Graft Surgery: The Use of Complementary Therapies
}

\author{
AMY L. AI, Ph.D., CHRISTOPHER PETERSON, Ph.D., and STEVEN F. BOLLING, M.D.
}

\begin{abstract}
This study explored the use of complementary therapies that patients pursued after coronary artery bypass graft (CABG) surgery and its relation to psychological recovery, particularly postoperative distress. Information about post-CABG surgery depression and general distress, health-care practice thereafter, perceived social support, and chronic conditions other than cardiac disease was gathered from a sample of 151 patients through two questionnaires. Additional cardiac, surgical, and demographic data were obtained from medical records. Structural equation modeling (LISREL 8) was used to test the hypothesis that patients' health-care practices improved psychological adjustment after CABG. Of the sample, $85 \%$ practiced complementary approaches, especially prayer, exercise, and lifestyle-diet modification. The number of other chronic illnesses strongly predicted post-CABG depression and general distress. CABG patients who pursued complementary approaches, particularly exercise and prayer, had better psychological recovery.
\end{abstract}

\section{INTRODUCTION}

$\mathbf{T}$ This study examined the use of complementary therapies among patients after coronary artery bypass graft (CABG) and its relation to psychological recovery. CABG surgery is one of the most frequently performed surgeries in the United States. Over 407,000 procedures are currently performed annually at a cost of over $\$ 5$ billion (American Heart Association, 1994; Politser and Cunico, 1988). The long-term clinical efficacy of CABG surgeries has been well established with respect to relieving symptoms. However, problems with psychological adjustment after CABG surgery have been evident in recent years. Lasting psychosocial complications may reduce the quality of life postoperatively. Se- vere neuropsychological outcomes immediately after $\mathrm{CABG}$ surgeries tend to be transient, but more subtle psychological impacts, especially depression, anxiety, fatigue, irritability, and sleep disorder, may last 6 months to 1 year or more (Eriksson, 1988, 1989; Folks et al., 1989; Lindal, 1990; Magni et al., 1987; Perski et al., 1991; Sokol et al., 1987; Townes et al., 1989; Venn et al., 1987).

The growing awareness of the unsatisfactory outcome of surgery has spurred the development of various rehabilitation programs for cardiac and post-CABG patients. Clinical research has demonstrated the considerable effect of psychological interventions and aggressive lifestyle modification in reversing advanced coronary heart disease (CHD) (Lewis, 1993; Ornish, 1993). With respect to post-CABG

University of Michigan, Ann Arbor, Michigan. 
psychological recovery, several types of psychological and behavioral interventions have undergone experimental examination. Crisis intervention was found to substantially alleviate depressions, fears, and suicidal thoughts and acts after CABG surgery (Pimm and Feist, 1984). Progressive relaxation training and short-term cognitive psychotherapy were reported to improve self-esteem and reduce depression (Valiant and Leith, 1986). Another study supported the contribution of a task-specific educational intervention (Beckie, 1989). The significant value of physical training, the most popular form of cardiac capacity rehabilitation, has also been documented in terms of improving functional capacity and psychological recovery (Dracup, 1991; Gulanick, 1989, 1991; Roviaro et al., 1984; Yusuf, 1988). More importantly, research confirmed that unsupervised home exercise is as effective and safe as gymnasium-based programs (Hands et al., 1987; Health et al., 1987). This low-intensity and cost-effective approach was particularly beneficial for older patients, especially due to their difficulties in transportation to gymnastic settings (King et al., 1991).

Despite these experiments, the extent to which typical CABG patients actually benefit from these psychosocial interventions remains unclear. A recent study revealed that only $15 \%$ of acute myocardial infarction (AMI) or CABG patients participated in group-based cardiac rehabilitation programs (DeBusk, 1992). Among participants, the drop-out rate at six months was as high as 50\% (DeBusk, 1993). Physicians were reluctant to make referrals because of their concerns about safety, and insufficient information about programs. Furthermore, little research attention has been devoted to self-initiated health-care practices of post-CABG patients and their effects on psychological adjustment. Few studies have explored CABG patients' perceptions for guidance of postdischarge management. Previous findings have indicated the wish by both CABG patients and their spouses for information concerning fatigue, risk factors, psychological effects, and deleterious effects of treatment (Juarsma et al., 1994; Moser et al., 1993). Some studies related postoperative maladjustment to patients' overly high expectations (Newman et al., 1987;
Waller et al., 1992), attributable to a shortage of information and support prior to CABG surgery (Hammond, 1984; Jaarsma et al., 1994; Townes et al., 1989).

The popularity of another type of health-care practice, complementary medicine, has been demonstrated in a nationwide survey (Eisenberg et al., 1993). Complementary medicine, also referred to as unconventional or alternative medicine, can be taken to mean any medical practice or intervention that: (1) does not have sufficient documentation; (2) is not taught in medical schools; and (3) is not generally reimbursable for third-party insurance billing (NIH Office of Alternative Medicine, 1994). Eisenberg et al. (1993) reported that about $34 \%$ of respondents used unconventional therapies for chronic medical conditions. However, $72 \%$ of them did not inform their medical doctors about their pursuit of alternative therapies. In 1990, Americans made approximately 425 million visits to these types of therapists, exceeding the number of visits to primary care physicians (388 million). Users of complementary medicine were younger, had college educations, and earned annual incomes above $\$ 35,000$. The sample in this survey underrepresented the population with poor health, which had a considerably higher rate of use of alternative therapy than those who reported better health (52\% vs. 33\%) (Eisenberg et al., 1993). There has been no investigation of the utilization of complementary approaches after CABG surgery.

Based on these findings, the present study sought to explore patients' utilization of healthcare practices, especially complementary approaches, in a CABG sample. The following research questions were addressed: (1) What health-care practices, especially complementary therapies, have patients pursued during the year after CABG surgeries? (2) What types of CABG patients have sought these forms of care? and (3) How are these practices related to their psychological recovery, particularly postoperative depression? For the second question, we expected that patients with higher socioeconomic status (education and income) would use complementary approaches (Eisenberg et al., 1993). Because postoperative psychological problems tended to be multifactorial rather than simply correlational (Eriksson, 1988, 1989; 
Folks et al., 1989; Lindal, 1990; Magni et al., 1987; Pelletier and Carrier, 1991; Perski et al., 1991; Sokol et al. 1987; Townes et al., 1989; Venn et al., 1987), an advanced statistical approach was used in this study for testing the third question. Through recursive path models created by LISREL 8 , the main effect of using complementary approaches was examined simultaneously with other possible contributors to psychological outcome (Jöreskog and Sörbom, 1993). In a hypothetical model (not shown), we anticipated that the use of complementary approaches would be linked to better psychological recovery 1 year after CABG surgery. Based on the previous findings, current psychological adjustment (1 year later) was also expected to be (1) positively associated with post-CABG depression (in the first month after the surgery), poorer health conditions, female gender, and age above 65 (a differentiation of the Medicare beneficiaries and nonbeneficiaries at the time of $C A B G$ ) and (2) negatively associated with higher social economic status (more education and income above $\$ 35,000$ ) and social support (Dean and Ensel, 1983; Eisenberg et al., 1993; Green et al., 1992; Holahan et al., 1995; Mahler and Kulik, 1991; Woodward and Wallston, 1987).

\section{METHOD}

\section{Patients}

The sample for this study was enlisted from the cardiac data registry at the University of Michigan Medical Center. Eligible candidates (aged 40 to 80 years) were 196 patients admitted for their first CABG only and discharged alive between January 1, 1993 and January 1, 1994. They had returned a 6-month follow-up questionnaire from the Department of Thoracic Surgery regarding their postoperative cardiac condition. For the present study, an additional questionnaire was sent to these 196 patients in 1995. It was completed by 151 patients (77\%); 2 patients had died, and 4 had moved.

\section{Procedure}

Retrospective information about patients was collected from three sets of data: a com- puterized database from the Medical Center and the two mailed questionnaires. Demographic data as well as surgical and medical information during hospitalization was obtained from the Department of Surgery. This information included age, gender, date of operation, left ventricular ejection fraction (LVEF), number of bypassed arteries, and death rate. Patients responded to two questionnaires. The first questionnaire, developed by the Section of Thoracic Surgery and completed at 6 months after the surgery, provided postoperative cardiac information. Developed for the current study, the second questionnaire was administered 1 year after the surgery and consisted of questions about: (1) background/socioeconomic information (e.g., education, family income, employment, and marital status at CABG surgery); (2) noncardiac chronic illnesses and self-rating health (both before CABG and at current time); (3) perceived social support after CABG surgery; (4) healthcare practices, especially complementary approaches, within 12 months after CABG surgery; (5) post-CABG depression in the month immediately after CABG; and (6) current psychological adjustment, defined as depression and general distress. Both questionnaires were sent and returned by mail.

\section{Measures}

Psychological adjustment. General distress and depression were measured with the Symptom Checklist-90-R (Derogatis, 1977). This instrument, designed to detect symptoms in a broad spectrum of individuals from apparently "normal" people to various types of medical patients, has been used extensively for psychological distress among medical, nonmedical, nonpsychiatric, and psychiatric populations (Bonynge, 1993; Bosse et al., 1987; Meyer et al., 1987; Newmann et al., 1990), including CABG patients (Hagen, 1989). Test-retest correlation coefficients for the subscales of this measure range from 0.78 to 0.90 , and internal consistency alpha coefficients from .77 to .90 . We used the total SCL-90-R score as a measure of general distress (Cyr et al., 1988; Rief and Fichter, 1992; Rief et al., 1991). The depression subscale was used as the depression index. Due 
to time limitation, the overall measure of general distress was addressed at only one time period, ie, at the current month (at least 1 year after CABG surgery). In an additional section, the depression subscale was presented again and asked about the month after CABG. A retrospective measure of postoperative depression in this study is not ideal due to possible recall bias. However, it was desirable to have a baseline estimate of dysphoria in case that patients with more mental health issues immediately following surgery might have been more likely to pursue complementary interventions. Only raw scores were used.

Social support. Social support was measured by the Multidimensional Scale of Perceived Social Support (MSPSS) (Zimet et al., 1988). The MSPSS is a self-report instrument evaluating subjective assessment of social support. It has been used with different populations and has good reliability, factorial validity, and adequate construct validity. Cronbach's coefficient alphas for the MSPSS are .91 for the total scale and .90 to .95 for the subscales. Three sources of support are measured through three subscales (family, friends, and significant others) with a higher score corresponding to higher support. This study used only the total score, because no significant differences were found among subscale scores.

Complementary therapies. Patients were asked whether they sought health-care practices in forms of complementary therapies for health / mental health problems during the year after CABG. Using YES and NO answers, they indicated the use of 16 unconventional therapies investigated by Eisenberg et al. (1993), including lifestyle-diet change, exercise, and prayer. The choice of a dichotomous answer instead of a scaled one was made for three reasons: (1) given the age range of the sample, a dichotomized indicator would be less affected by recall bias; (2) the primary interest of the study was CABG patients' pursuit of care rather than the efficacy of a specific service; and (3) the quantitative measure of each service might not be additive as a whole, if each were measured by continuous scales. Patients were also asked about their motivations or reasons for seeking specific types of practices and whether their physicians made a referral to each practice that they pursued.

Health conditions. In order to measure health status that was affected by noncardiac issues, we included 15 principal chronic conditions commonly seen on geriatric units. $\mathrm{Pa}-$ tients were also requested to make a 5-level rating of general health condition (excellent, very good, good, fair, and poor), both before the operation and currently. Cardiac complications were represented by symptoms on the 6-month follow-up, including self-ratings of cardiac condition, angina, fatigue, shortness of breath, swelling, congestive heart failure, irregular cardiac rhythm, and stroke. All items were coded dichotomously, except cardiac condition which was rated on a 4-level scale of severity. LVEF and number of bypassed arteries were used as indicators of preoperative health.

Background information. A dichotomized variable split at 65 years old was used to differentiate the Medicare beneficiaries and nonbeneficiaries at the time of CABG. In the study by Eisenberg et al. (1993), an income level cut at $\$ 35,000$ and college education were used to predict the utilization of unconventional medicine. To be consistent, dichotomized variables, eg, income cut at $\$ 35,000$ and college education, were used for the present study.

\section{Data Analysis}

First, descriptive and summary statistics were computed, as appropriate. The second type of statistical analysis involved inferential methods, including $t$-tests and bivariate correlations. Multiple logistic analyses were used to determine predictors of dichotomous variables in the model, e.g., use of complementary approaches. A power-analysis was computed for the multiple regression analysis. The effective sample size, $N$, to achieve .80 power was 147 at $\mathrm{a}=.01$ (two-sided), if 8 predictors were included in a model. Finally, models were generated using LISREL 8 computer software (Jöreskog and Sorbom, 1993). For the LISREL path model, a correlation matrix of input variables was used to obtain standardized path coefficients (beta coefficients). The total and indirect effects as well as $t$-values for each 
exogenous variable were calculated. Because the hypothetical model specified the direction of predictive effects, one-tailed probability levels were used to indicate the significance of each path coefficient. The evaluation of model fit used cross-fit indices and comparative-fit indices, such as the goodness-of-fit index (GFI), the adjusted goodness-of-fit index (AGFI), root-mean-square residual (RMR), normed fit index (NFI), and comparative fit index (CFI), as well as critical $\mathrm{N}(\mathrm{CN})$ as recommended (Bogozzi and Yi, 1988; Roykov et al., 1991).

\section{RESULTS}

\section{Sample characteristics and health conditions}

There were 112 males (74\%) and 39 females (26\%). One hundred and forty-seven were Caucasians (97\%), 3 were African-Americans (2\%), and 1 was Hispanic (1\%). Average age was 64.7 years $(\mathrm{SD}=8.8$ ), with a range from 40.8 to 80.8 . Medicare beneficiaries, people at age above 65 years old, accounted for $49 \%$ of the sample at CABG surgery. The majority of patients $(74 \%)$ were married. Full-time employment was 35\% at CABG surgery. Average education was 13.3 years $(S D=3.7)$, with a range from 4 to 24 years at the time of the surgery. Fifty-five patients $(36 \%)$ were college educated, and 62 $(41 \%)$ earned an annual family income above $\$ 35,000$. There was no statistical difference between patients who had returned or not returned two questionnaires concerning demographic, surgical, and cardiac conditions (except death rate).

All patients had undergone their first CABG without valvular diseases. The average bypass number was $3.7(\mathrm{SD}=1.12)$, with a range from 1 to 7 . The LVEF mean score was 47.2 (SD = 11.0 ), with a range from 15 to 80 . One-year mortality was $1.5 \%$ with a 1-year cardiac rehospitalization rate of $21 \%$. The 6-month follow-up indicated that the majority $(88.1 \%)$ of patients had no symptoms or a better heart condition than the pre-CABG condition. However, over one-third of them experienced fatigue, and over one-fourth had shortness of breath. Many patients also reported noncardiac chronic ill- nesses, such as insomnia (47\%), hypertension $(40 \%)$, arthritis $(37 \%)$, diabetes $(21 \%)$, and back problems $(21 \%)$. Wilcoxon matched-pairs signed ranks test suggested that current postCABG health-rating was improved $(z=$ $-3.5027, p<.0005,2$-tailed) in comparison with the preoperative health. A paired $t$-test showed a reduced current depression in comparison to the retrospective depression measure in the month following CABG $(t=9.7, p<$ .00005).

\section{Use of complementary approaches}

For the first research question, descriptive data revealed the type of health care practices that CABG patients followed. In the sample, $85 \%$ of patients practiced complementary approaches. A few of these types were most common: prayer $(67.5 \%)$, exercise $(45.7 \%)$, and lifestyle-diet modification (9.9\%). Other practices were reported by fewer than $10 \%$ of the respondents: individual counselor (6.6\%), chiropractic $(4.6 \%)$, self-health group (3.3\%), megavitamin therapy $(2.6 \%)$, massage $(2.6 \%)$, weightloss program $(2 \%)$, imagery (2\%), visiting clergy $(1.3 \%)$, and relaxation techniques (1.3\%). Single individuals $(0.7 \%)$ reported the following items: energy healing, biofeedback, homeopathy, acupuncture, or folk remedies.

\section{Predictors of using complementary approaches}

For the second research question, multiple logistic regressions were performed to explore the types of patients who pursued complementary approaches. The results showed that users of complementary approaches were more likely to believe in the importance of religion and to perceive higher social support. They also tended to be younger, to have a college education, and to earn less than $\$ 35,000$. However, the effects of these three variables were rather weak. The opposite direction of education and income in prediction to complementary approaches was unexpected. It was likely due to the fact that two most popular practices, e.g., exercise and prayer, were used by two different groups. Additional regression analyses were performed to discern the socioeconomic characteristics of these two types of patients. The only distinct predictor of practicing exer- 
cise was college education (Table 1), whereas using prayer was correlated with a higher importance placed on religion, age under 65 , better self-health rating, and lower income preoperatively (Table 2 ).

\section{Path models for the role of using complementary approaches}

For the third research question, structural equation modeling (LISREL 8) was used to test the effect of using complementary approaches. Standardized solutions for each path coefficient, model fit indices, and structural equations of Model 1 are indicated in Figure 1. Model 1 supported a significant inverse relation of complementary approaches with current distress $(b=-.09, t=1.93)$ and a strong effect of post-CABG depression in the month immediately after the surgery on current distress $(\mathrm{b}=.71, t=14.03)$. Model fit indices suggest a reasonably good fit of Model 1, as illustrated in Figure 1. The squared multiple correlation for this model suggested that $71 \%$ of current depression was explained.

As expected, the number of other chronic illnesses strongly predicted both post-CABG depression $(b=.48, t=6.69)$ and current distress $(\mathrm{b}=.21, t=4.09$ ). However, neither pre-CABG cardiac conditions nor cardiac symptoms at the 6-month follow-up varied with current distress. A subjective measure of health, preoperative self-health rating, did not predict postCABG depression nor was it significantly correlated with the objective measure, the number of other chronic illnesses. A partial correlation, controlling for education and income, showed that the number of other illnesses alone accounted for $22.5 \%$ of variation of post-CABG depression.

Most of other demographic and psychosocial variables, including age, marital status, preop- erative employment, and social support, were not associated with post-CABG depression or current distress (not shown). Inconsistent with our hypothesis, Model 1 did not find a direct effect of gender on depression as suggested previously (Dean and Ensel, 1983; Green et al., 1992; Holahan et al., 1995; Stallones et al., 1990). Gender influenced depression only when mediated through the number of other illnesses, and gender was the single predictor of the number of other illnesses. Two socioeconomic variables, education and income (a dichotomous variable dividing the sample at $\$ 35,000)$, both predicted post-CABG depression. Though correlated with each other $(r=$ $.45)$, these two measures appeared to affect post-CABG depression in different ways. Education had a negative effect $(b=-.14, t=$ 1.76), whereas income predicted a higher score of post-CABG depression $(b=.15, t=$ 1.81).

Model 2 indicated effects of the top two practices, exercise and prayer on current depression, shown in Figure 2. Model fit indices suggest a reasonably good fit of this path model. Both exercise and prayer had negative effects on current depression $(\mathrm{b}=-0.07, t=1.61$, and $\mathrm{b}=-0.08, t=1.71$, respectively). The two practices, however were not significantly correlated with each other $(r=-0.07)$. There was also a strong effect of post-CABG depression on current depression ( $b=0.75, t=15.06$ ). Standardized solutions for each path coefficient, model fit indices, and structural equations of this model can be found in Figure 2. The squared multiple correlation for this model suggested that $74 \%$ of current depression was explained. Finally, a third path model provided support for a negative association of prayer with general distress (not shown, $b=-.11$, $t=2.54$ ). Exercise was not associated with general distress.

Table 1. Multiple Logistic Regression Analysis for Predictors of Exercise

\begin{tabular}{lrrrrr}
\hline Variable & $B$ & S.E. & Wald & Significance & Odds ratio \\
\hline College education & 1.1603 & .3523 & 10.8479 & .0005 \\
Constant & -.6007 & .2134 & 7.9244 & .0050 \\
\hline
\end{tabular}

Note. $n=151$, overall $x^{2}=11.31, d f=1, p<.0008$. 
Table 2. Multiple Logistic Regression Analysis for Predictors of Prayer

\begin{tabular}{lrrrrr}
\hline Variable & $B$ & S.E. & Wald & Significance & Odds ratio \\
\hline Age $>65$ & -1.2744 & .4757 & 7.1761 & .0037 & .2796 \\
Income $>\$ 35,000$ & -.8719 & .4751 & 3.3690 & .0332 & .4181 \\
Importance of Religion & 1.1577 & .2524 & 21.0380 & .0000 & 3.1826 \\
Pre-CABG Health & -.5026 & .1949 & 6.6467 & .0050 & .6050 \\
Constant & .0017 & .9529 & 0.0000 & .4993 & \\
\hline
\end{tabular}

Note. $n=151$, overall $x^{2}=36.69, d f=4, p<.00001$.

\section{DISCUSSION}

The present study investigated health-care practices in the form of complementary approaches by post-CABG patients and their effects on psychological adjustment 1 year after the surgery. As suggested by Eisenberg et al. (1993), patients with medical problems used unconventional therapy more than the general population. About $85 \%$ of the patients in this sample pursued complementary therapies. The perceived health-rating and the level of post-CABG depression were much improved during the year after the surgery. Within this recovery process, patients who pursued com- plementary approaches, especially prayer and exercise, had a better present status (e.g., less depression or general distress) than those who did not. The findings imply that active engagement in this type of health-care practices may make a difference with respect to the psychological adjustment of post-CABG patients. Because previous research has revealed that depression may predict new cardiac events, including heart attack and surgical procedures, among patients with CHD (Carney et al., 1988), this finding is appealing. If the results in this study can be replicated through prospective studies and experimental investigations, new light may be shed on more effective post-

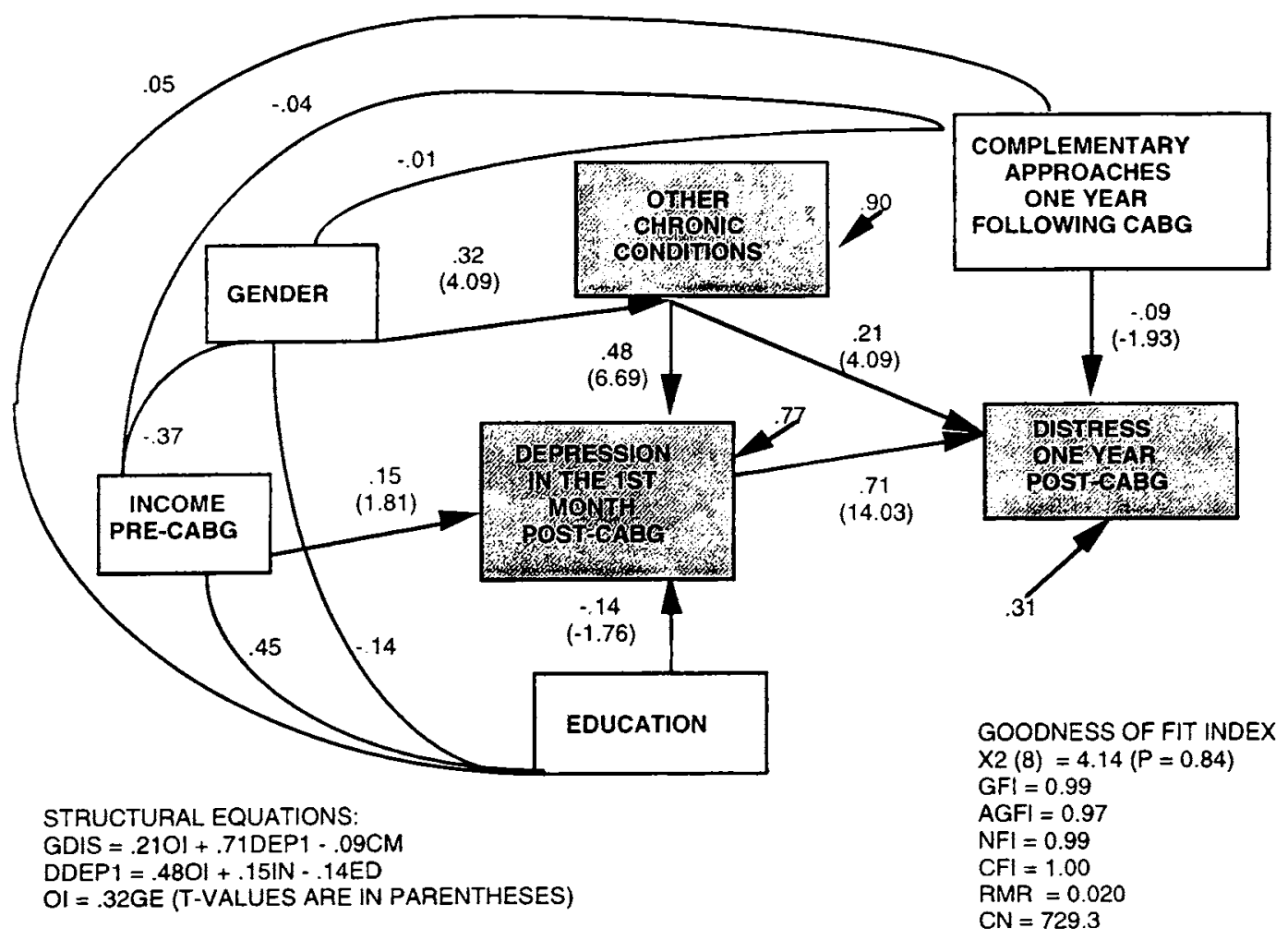

FIG. 1. Model 1 with complementary therapies predicting current distress. For this path diagram, a parameter in a darker box represents an endogenous variable and one in a lighter box represents an exogenous variable. A straight line with a single-headed arrow between boxes represents a direct effect; the path coefficient (b) and $t$-value (onetailed test) are also shown. A curved line between boxes represents a bivariate association; the correlation (r) is also shown. A single-headed arrow toward an endogenous variable represents a random disturbance. 


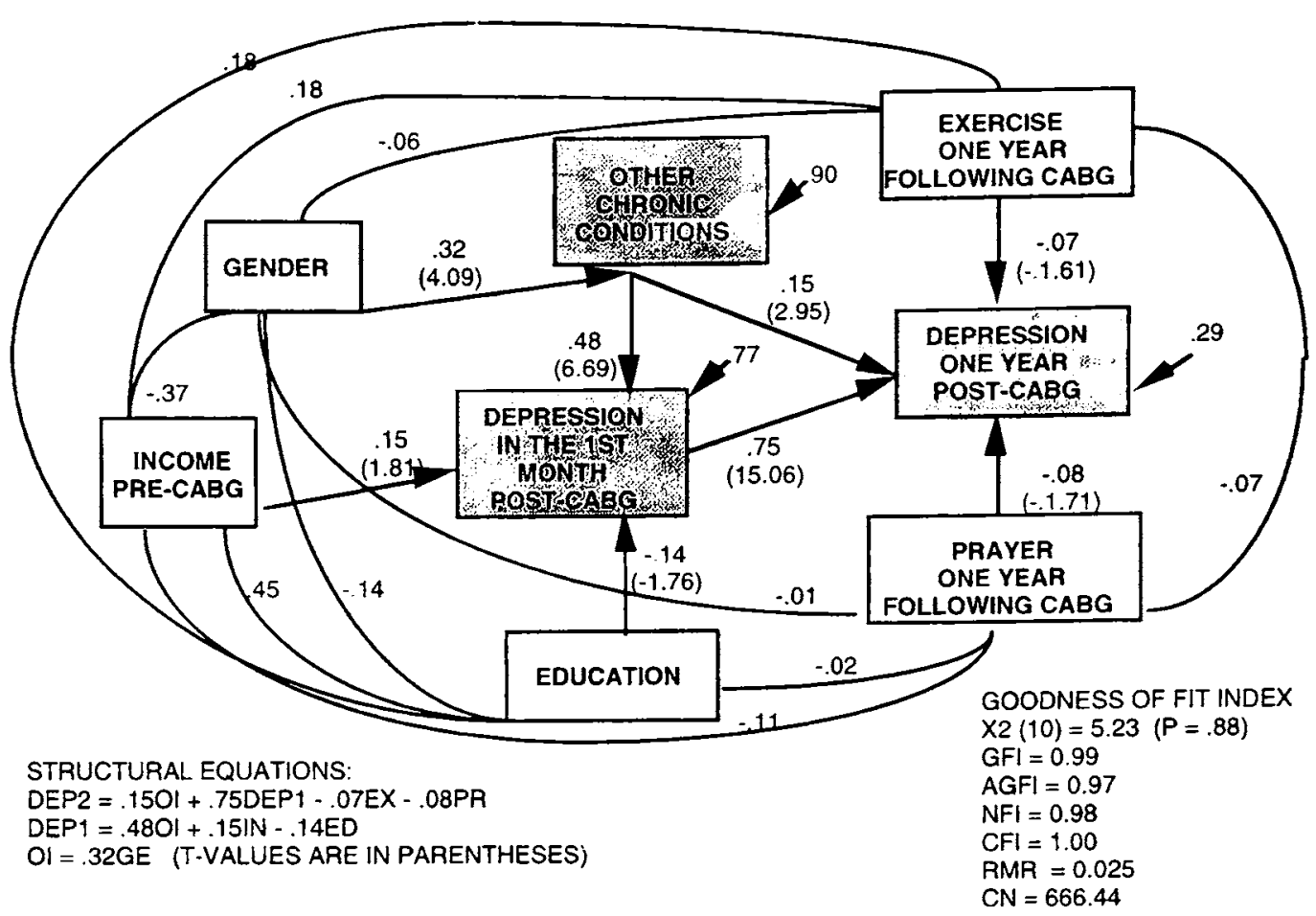

FIG. 2. Model 2 with exercise and prayer predicting current depression. See Fig. 1 for an explanation of the meaning of the different types of numbers and arrows.

CABG interventions and discharge management.

Despite these findings, the interpretation of the results needs to be cautious. The study was correlational rather than experimental; thus, it neither confirmed the effect of any particular type of complementary therapy nor explained why they worked. It should also be noted that not all of these practices were directly linked to cardiac problems. Some of these therapies, such as homeopathy, chiropractic, and acupuncture, were apparently sought for other chronic illnesses, although these conditions predicted post-CABG adjustment. However, exercise, prayer, and lifestyle-diet change were more closely associated with CABG or CHD related issues. The majority of the patients who exercised after surgery followed their primary doctors' advice, whereas the users of most other types of complementary approaches acted on their own wishes. The motivations for seeking such help were consistent with those documented by Eisenberg et al. (1993). These included perceived remedy, easy access, lower cost, fewer side-effects, better attention or care, and better control or choice, as well as other reasons, such as faith in God (for prayer) and prevention of second CABG (for patients who pursed exercise and lifestyle-diet change).
As for the type of patients who sought complementary approaches, the results showed negative influences of age and income and positive effects of education, importance of religion, and social support. Although age did not predict pursuing exercise in this sample, it may indirectly effect the engagement of older patients through a lower level of education. As predicted, education predicted higher engagement in complementary therapies, especially exercise. It also affected postoperative recovery through lower depression immediately following CABG. As suggested by previous research (Mahler and Kulik, 1991; Woodward and Wallston, 1987), the group with higher education may have better access to information on appropriate health care and better control of their own recovery, as revealed by their pursuit of complementary approaches. Well-educated patients may have the advantage of a better lifestyle and/or coping style both pre- and postoperative as well.

Unlike the finding in the study by Eisenberg et al. (1993) and inconsistent with our own hypothesis, income had a negative relation to complementary health-care practices. This result is likely explained by the fact that many patients who pursued prayer were poor, as shown in regression models predicting to ex- 
ercise and prayer, respectively. These analyses suggest that it is wise to examine each type of complementary approach separately. Finally, in previous studies, the effect of social support was primarily manifested over the first halfyear following the surgery (Coombs et al., 1989; Fontana et al., 1989; Kulik and Mahler, 1993). Our nonsignificant finding on this predictor is generally consistent and may suggest a more substantive need for long-term rehabilitation following the surgery. Additionally, the positive influence of social support on the use of complementary practices deserves more research attention. Perhaps social support from families and friends should be encouraged.

Several conceptual and methodological limitations should be noted. First, this exploratory study was retrospective, thus making causal conclusions tentative. In particular, the retrospective assessment of post-CABG depression was likely to be biased by recall. The correlation between these two variables, ie, postCABG depression and current psychological distress, thus is likely to be higher than its true value. However, the effect of another predictor, e.g., use of complementary therapies, may be suppressed in this path model and, thus, less likely to be exaggerated. Second, the study was unable to collect data to go beyond the hypotheses with respect to predictors of postoperative depression. It would be of great interest in the future to test other preoperative factors of psychological adjustment, such as depression and distress, health beliefs, coping styles, attitudes, personality traits, and other physiological indicators. Finally, the finding requires confirmation with other patient populations. It also needs to be compared with possible alternative models.

Despite these shortcomings, the analysis has provided some insights into postoperative psychological recovery among CABG patients. The positive role of complementary therapies calls our attention to effective postoperative management and to potential reduction of postoperative cardiac events and corresponding medical costs. The biomedical model of current health care is disease-centered. Technologically, medical services have become increasingly specialized in the United States. Subtle psychosocial problems after the surgery may not be of interest to many professionals. The findings in this study imply that health providers should pay more attention to an integrative picture of patients' rehabilitation. In an era of scant medical resources, complementary approaches may play protective roles in long-term rehabilitation, if they could be appropriately incorporated into professional care. Alternatively, patients' engagement in healthy behaviors or practices should also be encouraged by professional health-care providers in order to prevent worse outcome and to diminish risk factors, such as depression after this costly operation.

\section{ACKNOWLEDGMENTS}

We gratefully acknowledge the consultation of Duane Alwin, Ph.D., Ronald Kessler, Ph.D., Willard Rogers, Ph.D., Anthony Schork, Ph.D., Ruth Dunkle, Ph.D., Daniel Saanders, Ph.D., and John Spencer, Ph.D. on the research design. This work was supported in part by the National Institute on Aging Training Grant, T32-AG0017, and in part by the Research Partnership Program, the Rackham School of Graduate Studies, University of Michigan.

\section{REFERENCES}

American Heart Association 1994 Heart and Stroke Facts. American Heart Association, Dallas, TX.

Beckie T. A supportive-educative telephone program: Impact on knowledge and anxiety after coronary artery bypass graft surgery. Heart Lung 1989;18:46-55.

Bogozzi RP, Yi Y. On the eveluation of structural equation models. I Acad Market Sci 1988;16:74-94.

Bonynge ER. Unidimensionality of SCL-90-R scales in adjult and adolescent crisis samples. I Clin Psychol 1993;49:212-215.

Bosse R, Aldwin CM, Levenson MR, Ekerdt DJ. Mental health differences among retirees and workers: Findings from the normative aging study. Psychol Aging 1987;2:383-389.

Carney RM, Ruch MW, Freedland KE, Siani J. Major depressive disorder predicts cardiac events in patients with coronary artery disease. Psychosom Med 1988; 50:627-633.

Coombs DW, Roberts RW, Crist DA, Miller HL. Effects of social support on depression following coronary artery bypass graft surgery. Psychol Health 1989;3:29-35.

Cyr JJ, Doxey NC, Vigna CM. Factorial composition of the SCl-90-R. J Soc Behav Personality 1988;3:245-252. 
Dean A, Ensel WM. Social structured depression in men and women. Res Community Mental Health 1983;3: 113-139.

DeBusk $R$. Why is cardiac rehabilitation not widely used? West J Med 1992;156:206-208.

DeBusk R. Home-based and worksite-based exercise training for patients with coronary artery disease. Cardiol Clin 1993;11:285-295.

Derogatis LR 1977 SCL-90 Administration, Scoring \& Procedure, Manual-I for the R(evised) Version. Johns Hopkins University School of Medicine, Baltimore.

Dracup K, Moser DK, Marsden C, Taylor SE, Guzy PM. Effects of a multidimensional cardiopulmonary rehabilitation program on psychosocial function. Am I Cardiol 1991;68:31-34.

Eisenberg DM, Kessler RC, Foster C, Norlock FE, Calkins $\mathrm{DR}$, DelBanco TL. Unconventional medicine in the United States. New England Journal of Medicine 1993;328:246-52.

Eriksson J. Psychosomatic aspects of coronary artery bypass graft surgery: A prospective study of 101 male patients. Acta Psychiatr Scand 1988;77(Suppl 340):112.

Eriksson J. A psychosomatic approach to coronary bypass surgery. Psychiatr Fennicam 1989;20:111-118.

Folks DG, Blake DJ, Freeman AM, Sokol RS. Persistent depression in coronary bypass patients reporting sexual maladjustment. Psychosomatics 1989;29:387-391.

Fontana AF, Kerns RD, Rosenberg RL, Colonese KL. Support, stress, and recovery from coronary heart disease: A longitudinal causaI model. Health Psychol 1989;8: 175-193.

Green BH, Coeland JR, Dewey ME, Sarma V. Risk factors for depression in elderly people: A prospective study. Acta Psychiatr Scand 1992;86:213-217.

Gulanick ME 1989 Comparison of the effects of two exercise regimes and teaching/counseling on self-efficacy, physical activity performance, and exercise capacity. Unpublished dissertation. The University of Illinois.

Gulanick M. Is phase 2 cardiac rehabilitation necessary for early recovery of patients with cardiac disease? A randomized, controlled study. Heart Lung 1991; 20:9-15.

Hagen JW 1989 Patterns of psychological adjustment following coronary artery bypass graft surgery. Unpublished dissertation. The University of Wisconsin-Madison.

Hammond IW, Lee ET, Davis AW, Booze CF Jr. Prognostic factors related to survival and complication-free times in airmen medically certified after coronary surgery. Aviat Space Environ Med 1984;5:312-331.

Hands ME, Briffa T, Henderson K, et al. Functional capacity and left ventricular function: The effect of supervised and unsupervised exercise rehabilitation soon after coronary artery bypass graft surgery. L Cardiopulm Rehab 1987;7:578.

Health GW, Maloney PM, Fure CW. Group exercise verses home exercise in coronary artery bypass graft patients: Effects on physical activity habits. J Cardiopulm Rehab 1987;7:190.
Holahan CJ, Moos RH, Holahan CK, Brennan PL. Social support networks, coping, and depressive symptoms in a late-middle-aged sample of patients reporting cardiac illness. Health Psychol 1995;14:152-163.

Jaarsma T, Philipsen H, Kastermans MC, Dassen T. Information needs and problems of patients with myocardial infarct and coronary bypass. A study of information needs and problems from the view point of Orem's theory. Verpleegkunde 1994;8:233-242.

Jöreskog K, Sörbom, D 1993 LISREL 8: Structural Equation Modeling with the SMIPLIS Command Language. Scientific Software International, Inc, Chicago.

King AC, Haskell WL, Taylor CB, Kraemer HC, DeBusk RF. Group- vs home-based exercise training in healthy older men and women. JAMA 1991;266:1535-1542.

Kulik JA, Mahler HI. Emotional support as a moderator of adjustment and compliance after coronary artery bypass surgery: A longitudinal study. L Behav Med 1993;16:45-63.

Lewis SJ. Trends in cardiac care: Contractions, concentration, collaboration. AHA Hospital Technology Series 1993;12:1-29.

Lindal E. Post-operative depression and coronary bypass surgery. Int Disability Studies 1990;12:70-74.

Magni G, Unger HP, Valfre C, Polesel E, Cesari F, Rizzardo R, Paruzzolo P, Gallucci V. Psychosocial outcome one year after heart surgery: A prospective study. $\underline{\text { Arch }}$ Intern Med 1987;147:473-477.

Mahler HI, Kulik JA. Health care involvement preferences and social-emotional recovery of male coronary-arterybypass patients. Health Psychol 1991;10:399-408.

Meyer E, Derogatis LR, Miller M, Reading A. Hypertension and psychological distress. Psychosomatics 1987;19:160-168.

Moser DK, Dracup KA, Marsden C. Needs of recovering cardiac patients and their spouses: Compared views. Int J Nurs Stud 1993;30:105-114.

Newman SP, Smith P, Treasure T, Joseph P, Ell P, Harrison $M$. Acute neuropsychological consequences of coronary artery bypass surgery. Curr Psychol Res Rev 1987;6:115-124.

Newmann JP, Engel RJ, Jensen J. Depressive symptom patterns among older women. Psychol Aging 1990;5: $101-118$.

NIH Office of Alternative Medicine (OAM) 1994 Functional Description (301-402-4333).

Ornish D 1993 Part II. The opening your heart program. In Dr. Ornish's Program for Reversing Heart Disease: The Only System Scientifically Proven to Reverse Heart Disease without Drugs or Surgery. Random House, New York, pp. 133-352.

Perski A, Odlund SG, Rehanqvist N, Therorell T. The quality of life one year after by-pass operation [abstract]. International Symposium on Quality of Life after Open Heart Surgery, Antwerp, May 1991, p. 19.

Pimm JB, Feist JR 1984 Psychological Risks of Coronary Bypass Surgery. Plenum Press, New York.

Politser P, Cunico E 1988 Socio-Economic Factbook for Surgery. American College of Surgeons, Chicago.

Rief W, Fichter M. The Symptom CheckList SCL-90-R and 
its ability to discriminate between dysthymia, anxiety disorders, and anorexia nervosa. Psychopathology 1992;25:128-138.

Rief W, Greitemeyer M, Fichter MM. The Symptom Check List (SCL-90-R: Validation among 900 patients with psychosomatic disorders. Diagnostica 1991;37:58-65.

Roviaro S, Holmes DS, Holmsten RD. Influence of a cardiac rehabilitation program on the cardiovascular, psychological, and social functioning of cardiac patients. I Behav Med 1984;7:61-81.

Roykov R, Tomer A, Nesselroade JR. Reporting structural equation modeling results in psychology and aging: Some proposed guidelines. Psychol Aging 1991;6: 499-503.

Sokol RS, Folks DG, Herrick RW, Freeman AM. Psychiatric outcome in men and women after coronary bypass surgery. Psychosomatics 1987;28:11-16.

Stallones L, Marx MB, Martin B, Garrity TF. Prevalence and correlates of depressive symptoms among older U.S. adults. Am I Prev Med 1990;6:295-303.

Townes BD, Bashein G, Hornbein TF, Coppel DB, Goldstein DE, Davis KS, Nessly ML, Bledsoe SW, Veith RC, Ivey TD et al. Neurobehavioral outcomes in cardiac operations. L Thorac Cardiovasc Surg 1989;98:774-782.

Valliant PM, Leith B. Impact of relaxation-training and cognitive-therapy on coronary patients post surgery. Psychol Rep 1986;59:1271-1278.

Venn G, Klinger L, Smith P, et al. Neuropsychological sequelae of bypasses twelve months after coronary artery surgery. Br Heart J 1987;57:565.

Walter PJ, Mohan R, Dahan-Mizrahl S. Quality of life after open heart surgery 16-18 May 1991. Qual Life Res 1992;1:77-83.

Woodward NJ, Wallston BS. Age and health care beliefs: Self-efficacy as a mediator of low desire for control. Psychol Aging 1987;2:3-8.

Yusuf S, Wittes J, Friedman L. Overview of results of randomized clinical trials in heart disease. IAMA 1988;260:2259.

Zimet GD, Dahlem NW, Zimet SG, Farley GK. The Multidimensional Scale of Perceived Social Support. J Pers Assess 1988;52:30-41.

Address reprint requests to: Amy Ai, Ph.D. 1065 Frieze Building University of Michigan Ann Arbor, MI 48109-1285 
This article has been cited by:

1. Mary Jo Kreitzer, Mariah Snyder. 2002. Healing the Heart: Integrating Complementary Therapies and Healing Practices Into the Care of Cardiovascular Patients. Progress in Cardiovascular Nursing 17:2, 73-80. [CrossRef] 